\title{
A Bayesian prediction of four-look recognition performance from one-look data: II
}

\author{
STUART M. KEELEY, ${ }^{1}$ MICHAEL E. DOHERTY, AND SUZANNE P. BACHMAN \\ BOWLING GREEN STATE UNIVERSITY
}

In a recent paper, four-look recognition performance was predicted from one-look (IL) data by Bayes's theorem, with the entire pattern of two Ss' four-look data being predicted reasonably well. In the present study, three Ss were run, with the addition that feedback was given and confidence judgments were required. Their task was to identify tachistoscopically presented graphemes $A, T$, or $U$. Predictions of four-look performance were made using three orders of $I L$ data matrices, differing in the breakdown of confidence categories. The three matrices led to reasonably accurate predictions. Predictions varied somewhat in accuracy, depending on the order of the $1 L$ matrix. The possibility that the variation in predictive accuracy reflected the capacity of an $S$ to combine information received from each observation was discussed. The capacity question is presently under investigation by the authors.

Several models have been proposed to describe how a human observer (S) combines multiple observations to arrive at a single, overall decision about some state of the world (e.g., Eriksen, 1966; Swets \& Birdsall, 1968; Keeley \& Doherty, 1968 Doherty \& Keeley, 1969). The last-named report presented a model that is a direct application of Bayes's theorem to a visual-recognition task. When Ss were required to identify which of four visulal forms had been presented, the model predicted multiple-observation performance from single-observation performance. It was assumed that an S's response following multiple observations of a given stimulus was based on his judgment about the likelihood of each of the possible states of the world underlying the evidence he was obtaining. The S's single-observation data matrix provided estimates of the conditional probabilities of the occurrence of each response, given each of the specified stimuli. These single-observation responses were used to infer implicit responses on each observation in the multiple-observation condition. The individual implicit responses were assumed to represent the basic items of evidence. All possible sequences of such items of evidence were determined. The probability of each sequence (perceptual state, symbolized D) given each state $(H)$ of the world, $p(D / H)$, was calculated, using the single-observation conditional probabilities and assuming independence among observations. Theoretical posterior probabilities for all four states of the world were calculated from Bayes's theorem, and S's predicted multiple-observation response matrix was generated by assuming that Ss responded with the $\mathrm{H}$ with the greatest a posteriori probability. One of the desirable features of this approach to multiple-observation tasks is that the entire pattern of S's responding is predicted rather than some overall index, such as hit rate, (HR) or $\mathrm{d}^{\prime}$.

It was decided to replicate and to extend the research presented in Doherty and Keeley (1969) for several reasons. First, there were two respects in which the experimental design did not seem to provide an optimal test of the applicability of Bayes's rule. One of these was that no feedback was provided Ss. Since the model involves the mathematical combination of conditional probabilities, it seems that it would be given a more adequate test in an experimental situation that maximized the possibility of Ss' forming stable estimates of such probabilities. With repeated exposure to the evidence, immediate feedback should permit the $S$ to link the evidence with the state of the world more adequately. The other respect was that the prediction utilized only four implicit responses by $S$ to a given stimulus (the four responses corresponding to the four stimulus states). A response given with a high degree of certainty was treated in the same fashion as the same response representing a guess. In other words, the data from which predictions were made were relatively crude and did not adequately reflect the different levels of evidence discrimination that $S$ s are capable of making. It is likely that the more complete information we have concerning $S$ 's single-observation performance, the more accurate the predictions will be, providing $S$ can use all this information in combining or aggregating the evidence. An appropriate experimental operation to obtain more detailed single-observation information would be to require Ss to use confidence judgments in responding and in the predictions to treat each of the different judgments as defining a different implicit response.

Secondly, only two Ss were used in the previous investigations. In addition to giving the model a fairer test, this study provides data on additional Ss.

In summary, it is the purpose of this investigation to explore further the applicability of the Bayesian model as it was presented in Doherty and Keeley (1969), using a different set of visual stimuli, giving Ss immediate knowledge of results, and obtaining confidence judgments from the Ss.

Subjects

\section{METHOD}

Three students, two graduates and one undergraduate, served as paid Ss.

\section{Apparatus}

A Scientific Prototype Model GB tachistoscope, with a hand switch permitting $S$ to initiate stimulus onset, was the basic apparatus. A Hunter timer was wired into the circuit in order to keep presenting the stimuli at $1-\mathrm{sec}$ intervals as long as $S$ held the switch depressed. An audible click accompanied each stimulus presentation.

\section{Stimuli}

A black line, subtending a visual angle of approximately $.2 \mathrm{deg}$, on a white background, served as a fixation point. The white background and fixation point were illuminated at all times. The stimulus forms were the letters $A, T$, and $U$ from Letraset Sheet 441 . They were photographed using Kodalith film. The transilluminated negatives produced white forms on the white background. The forms subtended a visual angle of $.3 \mathrm{deg}$ and appeared directly above the fixation point.

\section{Procedure}

Viewing was monocular with S's preferred eye. Two experimental conditions were employed, one requiring a response after a single observation opportunity $(1 \mathrm{~L})$ and the other requiring a response after four opportunities to observe (1L4). In both conditions, S responded by naming the letter and by stating a confidence judgment indicating whether he "felt sure," "thought so," "was 
Table 1

Frequency of Each Response at Each Confidence Judgment to Each Stimulus for the IL Condition

\begin{tabular}{|c|c|c|c|c|c|c|c|c|c|c|}
\hline \multirow{3}{*}{ 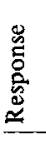 } & \multirow{3}{*}{ 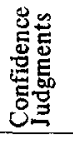 } & \multicolumn{9}{|c|}{ Stimuli } \\
\hline & & \multicolumn{3}{|c|}{ Subject 1} & \multicolumn{3}{|c|}{ Subject 2} & \multicolumn{3}{|c|}{ Subject 3} \\
\hline & & A & $T$ & $\mathrm{U}$ & A & $\mathbf{T}$ & $\mathbf{U}$ & A & $T$ & U \\
\hline a & $\begin{array}{l}1 \\
2 \\
3 \\
4\end{array}$ & $\begin{array}{r}36 \\
57 \\
5 \\
4\end{array}$ & $\begin{array}{r}4 \\
13 \\
5 \\
5\end{array}$ & $\begin{array}{r}1 \\
13 \\
8 \\
1\end{array}$ & $\begin{array}{r}2 \\
12 \\
95 \\
0\end{array}$ & $\begin{array}{r}0 \\
5 \\
49 \\
0\end{array}$ & $\begin{array}{r}0 \\
3 \\
47 \\
0\end{array}$ & $\begin{array}{r}1 \\
26 \\
79 \\
5\end{array}$ & $\begin{array}{r}0 \\
1 \\
27 \\
7\end{array}$ & $\begin{array}{r}0 \\
3 \\
32 \\
6\end{array}$ \\
\hline $\mathrm{t}$ & $\begin{array}{l}1 \\
2 \\
3 \\
4\end{array}$ & $\begin{array}{r}3 \\
33 \\
14 \\
9\end{array}$ & $\begin{array}{l}11 \\
65 \\
43 \\
28\end{array}$ & $\begin{array}{r}8 \\
37 \\
26 \\
15\end{array}$ & $\begin{array}{r}0 \\
9 \\
56 \\
0\end{array}$ & $\begin{array}{r}0 \\
21 \\
93 \\
1\end{array}$ & $\begin{array}{r}0 \\
9 \\
52 \\
0\end{array}$ & $\begin{array}{r}1 \\
11 \\
54 \\
12\end{array}$ & $\begin{array}{r}6 \\
27 \\
97 \\
27\end{array}$ & $\begin{array}{r}0 \\
3 \\
49 \\
26\end{array}$ \\
\hline $\mathbf{u}$ & $\begin{array}{l}1 \\
2 \\
3 \\
4\end{array}$ & $\begin{array}{r}3 \\
29 \\
5 \\
2\end{array}$ & $\begin{array}{r}0 \\
15 \\
20 \\
6\end{array}$ & $\begin{array}{r}15 \\
42 \\
12 \\
7\end{array}$ & $\begin{array}{r}0 \\
0 \\
30 \\
3\end{array}$ & $\begin{array}{r}0 \\
4 \\
32 \\
0\end{array}$ & $\begin{array}{r}0 \\
9 \\
67 \\
1\end{array}$ & $\begin{array}{r}0 \\
2 \\
18 \\
5\end{array}$ & $\begin{array}{r}0 \\
0 \\
10 \\
15\end{array}$ & $\begin{array}{r}3 \\
22 \\
55 \\
10\end{array}$ \\
\hline
\end{tabular}

guessing," or "saw nothing." These were announced by $S$ as " 1 ," " 2 ," " 3 ," or " 4 ," respectively. Stimulus presentation in the $1 \mathrm{~L}$ condition was initiated by $\mathrm{S}$ after a ready signal, which was the sound of the stimulus tray being inserted into the tachistoscope. In the $1 \mathrm{~L} 4$ condition, the onset of the first presentation was controlled by $S$, but the next three observation opportunities were programmed by a recycling timer to control the onset-onset interval within a trial. This interval was $1.0 \mathrm{sec}$. All Ss were extensively pretrained. The $\mathrm{E}$ manipulated the exposure duration in the $1 \mathrm{~L}$ pretraining trials to obtain a HR of approximately .50 . Then each $S$ was informed that he would receive a $\$ .50$ bonus for each experimental session in which his performance exceeded a criterion set by the Es. The criterion was not specified, and Ss were told that the bonus would be paid at the end of the experiment.

Feedback was then introduced by $E$ telling $S$ after each response which letter had actually been presented. Pretraining continued for several more sessions. Exposure durations were adjusted to correct for some slight improvement due to the bonus and feedback. These exposure durations were then maintained in all subsequent experimental sessions.

After pretraining was completed, 15 experimental sessions were run with two Ss and 16 with the third $S$. In each session, there were 80 experimental trials preceded by 10 practice trials. The 80 trials in each sessions were divided into two blocks, $401 \mathrm{~L}$ and $401 \mathrm{~L} 4$ trials. Order of blocks was counterbalanced across sessions.

\section{The Prediction Model}

Predictions were made according to Bayes's rule as described in Doherty and Keeley, 1969. The S's 1L data matrices were used to predict his $1 \mathrm{~L} 4$ performance. The only difference between the application of the model in Doherty and
Keeley (1969) and the present application is that, in this study, the 3 by $31 \mathrm{LA}$ matrix is predicted from $1 \mathrm{~L}$ data matrices that include confidence judgments. If $S$ were to distribute his judgments in such a fashion that stable conditional probabilities could be estimated for each possible stimulus-response pair at each confidence judgment, the prediction matrix would be 3 by 3 by 4 ( 3 stimuli by 3 responses by 4 confidence categories). This aspect of the procedure and some problems related to it are discussed below.

For each $S$, predictions of $1 \mathrm{~L} 4$ performance were made from three $1 \mathrm{~L}$ data matrices. These include: the 3 by 3 matrix, which does not take into account confidence judgments; a 3 by 3 by 2 matrix, in which the four confidence categories were collapsed into two; and the complete 3 by 3 by 4 matrix. Selection of the two confidence categories for the 3 by 3 by 2 matrix was made on the basis of an inspection of how the Ss were using the different rating categories in the $1 \mathrm{~L}$ condition (see Table 1). For example, in the case of S 1, the " 2 ," " 3 ," and " 4 " judgments differed little among themselves in accuracy as compared with the difference between the " 1 " judgments and the " 2, ," " 3 ," and " 4 " judgments. This suggests that the " 2 ," " 3 ," and " 4 " judgments represented similar evidence impact to S 1. Another criterion for selection of confidence categories for collapsing was that there be as many responses as possible in all cells. Using this procedure, confidence categories " 2 ," " 3 ," and "4" were collapsed for S 1. For the other two Ss, the two categories were composed by collapsing the " 1 " and " 2 " judgments into one category and the " 3 " and " 4 " into another.

\section{RESULTS}

Table 1 shows the three single-observation relative-frequency matrices for all Ss. The predicted $1 \mathrm{LA}$ matrices for each S's 3 by 3 by 2 L matrix, as well as the empirical $1 \mathrm{~L} 4$ matrices, are presented in Table 2 . Of the three orders of matrices, the 3 by 3 by 2 matrix provides the best predictions of the empirical data, the pattern of predicted results being markedly similar to the empirical data. The other two orders of input matrices also predict empirical data reasonably well. The overall HRs are presented in Table 3. Predictions from the 3 by 3 underpredict and from the 3 by 3 by 4 overpredict the empirical data for all three Ss. Order of the $1 \mathrm{~L}$ matrix has its greatest effect on the predictions for Ss 1 and 3 , who tended to discriminate to a greater degree among the four confidence categories. Predicted HR increases in all cases as a function of an increase in the order of the matrix, as one would expect if rating categories represent differential evidence impact.

\section{DISCUSSION}

The above-described application of Bayes's rule predicts four-observation performance extremely accurately from an S's single-observation data. The three Ss in this study make a total of five who have been run over a large number of both single- and multiple-observation trials in a visual-recognition task, using an alphabet of four stimuli (Doherty \& Keeley, 1969) and of three stimuli (present investigation). In all five cases, the model has provided a very close fit to the obtained multiple-observation data matrices.

An interesting result of this investigation

Table 2

Empirical and Predicted (a', t', u') Frequencies of Each Response to Each Stimulus State for the IL4 Condition, Predicting from the 3 by 3 by 2 IL Matrix

\begin{tabular}{|c|c|c|c|c|c|c|c|c|c|}
\hline \multirow[b]{3}{*}{ Response } & \multicolumn{9}{|c|}{ Stimulus State } \\
\hline & \multicolumn{3}{|c|}{ Subject 1} & \multicolumn{3}{|c|}{ Subject 2} & \multicolumn{3}{|c|}{ Subject 3} \\
\hline & A & $\mathrm{T}$ & $\mathrm{U}$ & A & $T$ & $\mathbf{U}$ & $\mathrm{A}$ & $\mathbf{T}$ & $\mathrm{U}$ \\
\hline $\begin{array}{l}a_{1} \\
a^{\prime}\end{array}$ & $\begin{array}{l}149 \\
150\end{array}$ & $\begin{array}{l}17 \\
20\end{array}$ & $\begin{array}{l}38 \\
18\end{array}$ & $\begin{array}{l}151 \\
139\end{array}$ & $\begin{array}{l}46 \\
48\end{array}$ & $\begin{array}{l}55 \\
38\end{array}$ & $\begin{array}{l}173 \\
155\end{array}$ & $\begin{array}{l}30 \\
28\end{array}$ & $\begin{array}{l}35 \\
28\end{array}$ \\
\hline $\mathrm{t}$ & $\begin{array}{l}20 \\
27\end{array}$ & $\begin{array}{l}148 \\
138\end{array}$ & $\begin{array}{l}59 \\
72\end{array}$ & $\begin{array}{l}37 \\
45\end{array}$ & $\begin{array}{l}117 \\
125\end{array}$ & $\begin{array}{l}30 \\
47\end{array}$ & $\begin{array}{l}21 \\
30\end{array}$ & $\begin{array}{l}164 \\
159\end{array}$ & $\begin{array}{l}34 \\
30\end{array}$ \\
\hline $\begin{array}{l}\mathbf{u}^{\prime} \\
\mathbf{u}^{\prime}\end{array}$ & $\begin{array}{l}26 \\
15 \\
\end{array}$ & $\begin{array}{l}23 \\
30 \\
\end{array}$ & $\begin{array}{l}120 \\
127 \\
\end{array}$ & $\begin{array}{l}19 \\
23 \\
\end{array}$ & $\begin{array}{l}42 \\
32 \\
\end{array}$ & $\begin{array}{l}103 \\
104 \\
\end{array}$ & $\begin{array}{l}16 \\
25\end{array}$ & $\begin{array}{l}16 \\
25 \\
\end{array}$ & $\begin{array}{l}149 \\
160 \\
\end{array}$ \\
\hline
\end{tabular}


Table 3

Empirical and Predicted Overall Proportion of Correct Responses in the IL4 Condition for Each of Three Orders of Input Matrix

\begin{tabular}{cccc}
\hline & \multicolumn{3}{c}{ Subject } \\
\cline { 2 - 4 } & 1 & 2 & 3 \\
\hline $\begin{array}{c}\text { Empirical HR } \\
\text { Predicted HR - } \\
\text { Order of Input } \\
\text { Matrix } \\
3 \text { by 3 }\end{array}$ & .695 & .610 & .759 \\
3 by 3 by 2 & .692 & .613 & .741 \\
3 by 3 by 4 & .735 & .622 & .775 \\
\hline
\end{tabular}

is the systematic quality of the predictions from different-order input matrices. As one would expect from the model, the more rating categories included in the single-observation input matrix, the greater the $1 \mathrm{LA}$ predicted $\mathrm{HR}$. When all four rating categories are included in the input matrix, the model overpredicts in all cases; when ratings are omitted, the model underpredicts; and when the four rating categories are collapsed into two by the Es, essentially on the basis of differential evidence impact of the categories, the predictions fit extremely closely. The closeness of fit provided by this specific order of input matrix may be due to chance. However, the results may be amenable to a more lawful explanation, subject to further verification. It may be under the regularity displayed in the underprediction of all three $S s$ by the 3 by 3 matrix, the good prediction by the 3 by 3 by 2 , and the overprediction by the 3 by 3 by 4 reflects a limitation on the capacity of the $\mathrm{Ss}$ to combine the information they are getting from the several observations.

It seems to the authors that one possibly explanation for the goodness of fit of the 3 by 3 by 2 matrix in this investigation is that it represents more closely S's use of the evidence in the multiple-observation task. Thus, the 3 by 3 by 4 overpredicts multiple-observation performance because the $\mathrm{S}$ cannot use all the evidence associated with each observation that he can use in a single-observation task. In essence, the sensory events may be grouped more grossly in the multiple-observation task in order to reduce the demands of the decision task. The $S$ may be using more information than that represented by the 3 by 3 matrix and less than that represented by the 3 by 3 by 4 . An obvious, but very ambitious, test of the capacity notion is to vary the number of stimuli, responses, and rating categories systematically. A simple assumption to start out with would be that the number of cells in the prediction matrix is an important factor, irrespective of whether the cells represent more stimulus categories or more response categories. It may be significant that the number of cells (16) in the prediction matrix in Doherty and Keeley (1969) that led to very good predictions was approximately equal to the number (18) that led to the best prediction in this study. The capacity question is an interesting one and is being investigated further by the authors. We see this as one important aspect of the general question of under what conditions Ss combine information optimally and under what conditions they fail to.

In asking these questions and in applying the Bayesian model to this type of experimental task, we are addressing ourselves to the problem of how Ss evaluate and aggregate evidence that may be represented probabilistically. These questions are presently being investigated in very different experimental frameworks by Edwards and others (see, for example, Edwards, 1968) and Schum and his colleagues (see, for example, Schum \& Martin, 1968). These investigators have focused primarily on the ability of $S$ to revise an opinion about the probability of some state of the world as new evidence emerges. Their primary method has been to compare S's subjective posterior probabilities of the true state of the world $\left(\mathrm{H}_{\mathrm{T}}\right)$, with a Bayesian calculation of the posterior probability. Typically, Ss are presented samples of evidence from a given $\mathrm{H}_{\mathrm{T}}$ and asked to state their confidence that it came from $H_{T}$ in the form of a probability estimate. In contrast, as we are using the Bayesian model, the probabilities of $\mathrm{D} / \mathrm{H}$ [which may be seen as analogous to $D / H$ in Schum and Martin (1968), where D represents an entire set of evidence, or a scenario] are calculated directly from an S's single-observation matrix. Rather than presenting $S$ a set of evidence from some $H$ and asking for a posterior probability of $H_{T}$, the evidence sets are assumed to be determined by the single-observation conditional probabilities. Ss are not asked to state posterior probabilities or odds. They are asked to state decisions that are assumed to be dependent upon the posterior probabilities. The model is tested by comparing the pattern of obtained decisions to the pattern of decisions predicted by the model, which assumes that $S$ always chooses the most likely state of the world, given the available evidence.

\section{REFERENCES}

DOHERTY, M. E., \& KEELEY, S. M. A Bayesian prediction of four-look recognition performance from one-look data. Perception \& Psychophysics, 1969, 5, 362-364.

EDWARDS, $w$. Conservatism in human information processing. In B. Kleinmuntz (Ed.), Formal representation of human iudrment. New York: Wiley, 1968. Pp. 17-52.

ERIKSEN, C. W. Independence of successive inputs and uncorrelated etror in visual torm perception. Journal of Experimental Psychology, 1966, 72, 26-35.

KEELEY, S. M., \& DOHERTY, M. E. Simultaneous and successive presentations of single-featured and multi-featured visual forms: Implications for the parallel processing hypothesis. Perception \& Psychophysics, 1968, 4, 296-298.

SCHUM, D. A., \& MARTIN, D. W. Human processing of inconclusive evidence from multinomial probability distributions. Organizational Behavior \& Human Performance, 1968, 3, 353-365.

SWETS, J. A., \& BIRDSALL, T. G. Deferred decision in human signal detection: A preliminary experiment. Perception \& Psychophysics, 1967, 2, 15-28.

\section{NOTE}

1. Address: Department of Psychology, Bowling Green State University, Bowling Green, Ohio 43402.

(Accepted for publication June 27, 1969.) 